\title{
EFFECT OF AM FUNGI WITH ADDITONAL PHOSPHATE FERTILAZATION ON GROWTH AND NUTRIENT UPTAKE IN GUIZOTIA ABYSSINICA (L.F) CASS.VAR, RCR-18
}

\author{
Gabriel K P1, H C Lakshman², TanzimaYeasmin ${ }^{3}$ \\ 1,2Microbiology Laboratory, P.G. Department of Studies in Botany \\ Karnataka University, Dharwad-580003, Karnataka, India \\ 3Institute of Biological Sciences, University of Rajshahi, Rajshahi -6205, Bangladesh
}

\begin{abstract}
Context: Arbuscular-Mycorrhizal fungi colonization in roots of many plants promotes the increased nutrient uptake especially the phosphorus from phosphorus deficient soil.

Objective: To compare the efficacy of different concentration of recommended dosages of super phosphate fertilizers with inoculation of AM fungi to evaluate growth, nutrients uptake on Niger plant (Guizotia abyssinica (L.f) Cass. var, RCR-18).

Materials and Methods: The effect of two Arbuscular mycorrhizal fungi Scutellospora nigra and Glomus mosseae with 4 different dosage $(25 \%, 50 \%, 75 \%, 100 \%)$ of superphosphate $\left(\mathrm{P}_{2} \mathrm{O}_{5}\right)$ was treated on growth yield and nutrient uptake in Niger plant (Guizotia abyssinica (L.f) Cass. var, RCR-18) was evaluated under greenhouse conditions. Pots were watered they were harvested once in 30 days intervals. For 90 days the following readings viz., plant height, root length, biomass, grains yield, percent root colonization, spore number macro-micro nutrients contents in shoots and roots were determined.

Results: Scutellospora nigra with 50\% RDSP/kg showed a significant increase in the plant growth biomass of shoot and root of Guizotia abyssinica (L.f) Cass. var, RCR-18. Percent root colonization, seed number and N, P, K and Zn, Mg uptake in shoot and root.

Conclusion: Overall, our results clearly suggest that synergistic and additive mechanisms involved can enhances the plant growth, nutrient uptake and adaptation to unfavorable drought soil conditions.
\end{abstract}

Key words: Arbuscular mycorrhizal (AM) fungi, Niger plant, Biomass yield, Root colonization, Nutrient uptake, Scutellospora nigra, Glomus mosseae.

\section{Introduction}

Many good numbers of crop plants fail to absorb the nutrients from the soil which is present beyond the root zone of active absorption. Most land plants form association with Mycorrhizal fungi. Mycorrhizas are mutualistic associations between fungi and plant roots .they are described as symbiotic because the fungus receives photosynthetically derived carbon compounds and plant has increased access to mineral nutrients and sometimes water (Brundrett et al.1996). Arbuscular-Mycorrhizal fungi colonization in roots of many plants promotes the increased nutrient uptake especially the phosphorus from phosphorus deficient soil (Bagyaraj 2006, Lakshman 2008). AM fungi could increase the absorption of phosphorous to the host plant and in turn obtain carbon from the host plant (Kapoor et al. 1989, Fusconi et al. 2005, Tanwar 2012). Ross (1971) has studied the effect of phosphate fertilizer on yield of mycorrhizal and non-mycorrhizal soybean plants. Phosphorus is the major element required by the crop plants and mycorrhizal plants utilize ' $P$ ' from organic matter (Jones and Jacobson 1995, Smith 2011). Mosse (1973) have observed that the mycorrhizal onion seedlings grew better in both sterilized soils when compared to non mycorrhizal plants. Recently Tanwar (2013) has studied the effects of AM fungi in the superphosphate fertilization on growth and yield of bell pepper Capsicum annum var. California wonder. Hence, this investigation was undertaken in green

\footnotetext{
* Corresponding author E-mail: gkgary777@gmail.com
} 
house conditions to compare the efficacy of different concentration of recommended dosages of super phosphate fertilizers with inoculation of AM fungi to evaluate growth, nutrients uptake on Niger (Guizotia abyssinica (L.f) Cass. var, RCR-18) with an aim to reduce the applications of chemical fertilizers for sustainable system.

\section{Materials and Methods}

Guizotia abyssinica (L.f) Cass.var, RCR-18 seeds were surface sterilized in 1\% sodium hypo chlorite and rinsed 2-3 times in distilled water and they were sowed in earthen pots, each earthen pots measuring $(15 \times$ $20 \mathrm{~cm}$ ) (breadth $\times$ length) filled with four $\mathrm{kg}$ sterile phosphorus deficient soil. Chemical composition of this soil consists in the ratio of phosphate- $5.3 \mathrm{ppm} / \mathrm{kg}$, nitrogen $=11.7-\mathrm{ppm} / \mathrm{kg}$ soil, potassium $=14.6 \mathrm{ppm} / \mathrm{kg}$, E.C $=0.05 \mathrm{mmhos} / \mathrm{cm}^{2}, O . \mathrm{M}=0.19 \%$. The soil in the ratio of $3: 1$ proportion ( 3 parts of sandy loam soil and 1 part of pur sand was fumigated and sterilized by using $5 \%$ methyl bromide).

Two indigenous strains of AM fungal species viz., Scutellospora nigra and Glomus mosseae were selected for the present experiments and these were mass multiplied with the host Rhode grass (Chloris gayana Munch) 15 grams of mixed inoculums was placed $4 \mathrm{~cm}$ below the surface of each experimental pots, except the control pots. The inoculums consisted of $7.5 \mathrm{gm}$ of infected root bits plus $7.5 \mathrm{gm}$ of rhizospheric soil. Approximately $5 \mathrm{gm}$ of rhizospheric soil contained hyphae, sporocarp and spores 135 - 215 chlamydospores. Experimental plants were arranged in completely randomized design with four replications and treated with four different levels of phosphate. The recommended dose (PRD) of super phosphate $\left(\mathrm{P}_{2} \mathrm{O}_{5}\right)$ for Niger was found to be $40 \mathrm{~kg}$ per hectare (ha).

The following treatments were carried out as mentioned below.

1. Zero P O (Control)

2. $25 \%$ PRD $P_{2} 0_{5}(0.20$ g per $8 \mathrm{~kg}$ soil) + AMF

3. $50 \% \mathrm{PRD} \mathrm{P}_{2} \mathrm{O}_{5}(0.40 \mathrm{~g}$ per $8 \mathrm{~kg}$ soil $)+\mathrm{AMF}$

4. $75 \% \mathrm{PRD} \mathrm{P}_{2} \mathrm{O}_{5}(0.80 \mathrm{~g}$ per $8 \mathrm{~kg}$ soil $)+\mathrm{AMF}$

5. $100 \% \operatorname{PRD~P}_{2} \mathrm{O}_{5}(0.160 \mathrm{~g}$ per $8 \mathrm{~kg}$ soil $)+\mathrm{AMF}$

An application of fertilizers was made as per the standard method proposed by (Kaleem 2000). Pots were watered whenever, it needed and they were harvested once in 30 days intervals. For 90 days the following readings viz., plant height, root length, biomass, and grains yield, percent root colonization, spore number macro-micro nutrients contents in shoots and roots were determined. Percent root colonization; and staining roots was done after washing the roots under tap water and cut in $1 \mathrm{~cm}$ pieces and mixed in $10 \% \mathrm{KOH}$, autoclaved for 30 minutes and washed in distilled water in 2-3 times, and neutralized in $2 \mathrm{~N} \mathrm{HCl}$ for 2 minutes, later stained in $0.05 \%$ tryphan with lacto phenol following the procedure (Phillips and Hayman 1970, Giovennette and Mosse 1980). Plant dry weight was measured after the plant material was oven dried for 72 hours at $70^{\circ} \mathrm{C}$. Number of seeds was counted from each flower of the plants. AM fungal spores were isolated according to wet-sieving decanting technique (Gerdemann and Nicolson 1963). Phosphorus content of the shoot was determined calorimetrically by the vanadomolybdate phosphoric - yellow colour method outlined by (Jackson, 1973). Total nitrogen determinations were made by the Microkjeldahal method (Bremmer, 1960). Micronutrients Zn and Mg were determined by using GBS 902 atomic absorption spectocalorimeter.

\section{Results and Discussion}

The results of the treatments and growth parameters viz., plants height, biomass yield, per cent root colonization, spore number, macro and micronutrient content of shoot and root is presented in Table 1. 


\title{
Space for Table 1 (Landscape) to be inserted from
}

\author{
File name: Table 1 Gabriel paper P-7
}

Guizotia abyssinica (L.f) Cass.var, RCR-18 showed 50\% RD sp/kg with mycorrhizal inoculation significantly influenced the increase plant growth, dry weight of shoot and root; percent root colonization, spore number, N.P.K. and Zn, Mg uptake in shoot and roots. Secondly 75\% RDSP/kg with mycorrhiza Scutellospora nigra influence in biomass yield and nutrient uptake. The seeds production was higher (1610/plant) in Niger plants at $75 \% \mathrm{RDSP} / \mathrm{kg}$ with mycorrhiza, followed by $100 \% \mathrm{RDSP} / \mathrm{kg}$ with mycorrhiza inoculation influenced for Niger lower number of seeds 501 /plant production. This improvement in Guizotia abyssinica plants showed significant results with mycorrhizal inoculation and no such improvement in plant growth, biomass yield, seeds in non inoculated or control plants. Overall Guizotia abyssinica (L.f) Cass.var, RCR-18 increased biomass when compared to the control plants (Figures 1-5). 

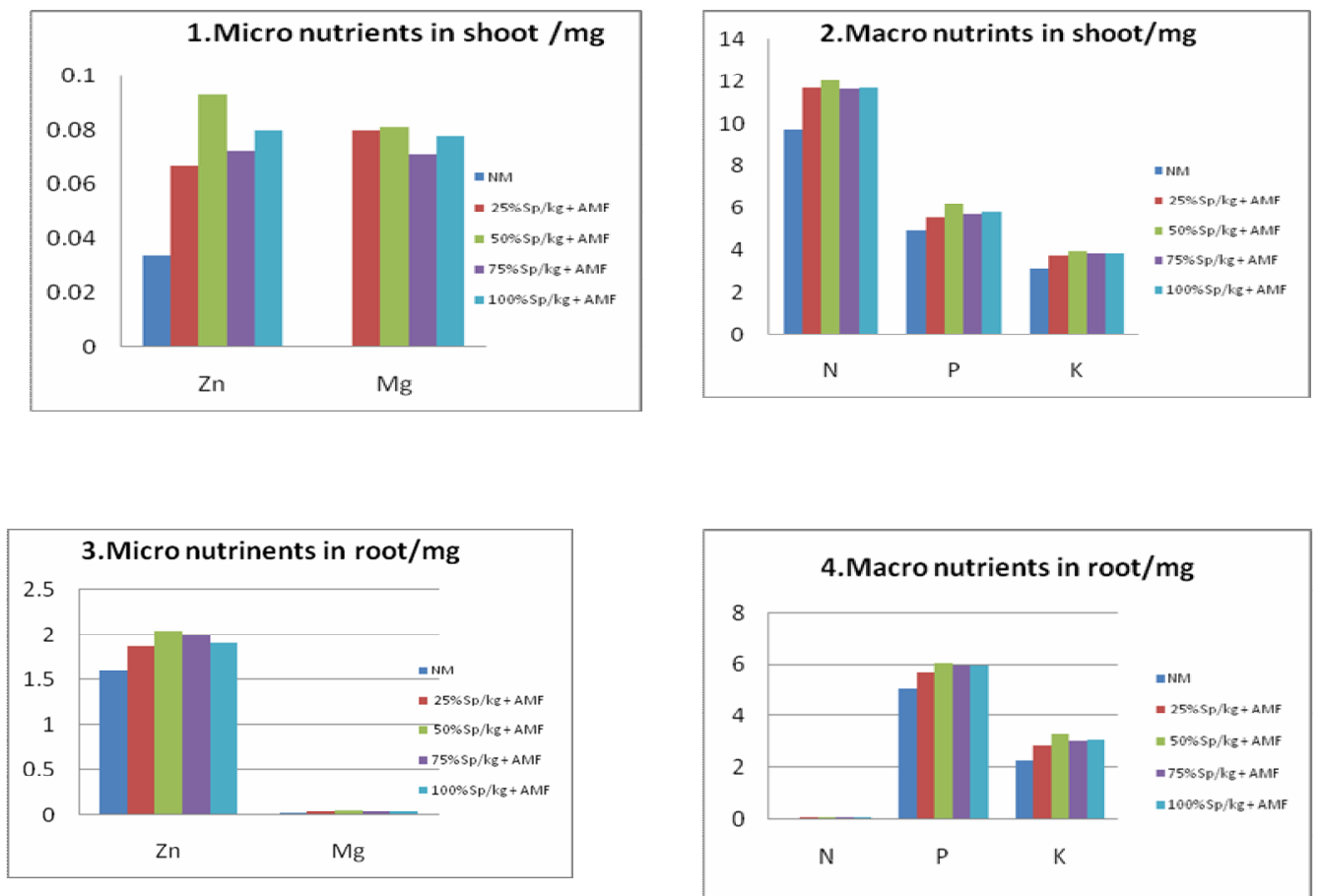

Fig. 1, 2, 3 \& 4. : Effect of micro and macro nutrient on growth of Guizotia abyssinica (L.f) Cass RCR-18 var at 90 days with different dosages of phosphate and AM fungus Scutellospora nigra, Glomus mosseae.

The magnesium $(\mathrm{Mg})$ was found to be higher in control non inoculated plants than the plants treated with phosphate and inoculated with AM fungi. However, increase in concentration of $\mathrm{N}, \mathrm{K}, \mathrm{Zn}$ and $\mathrm{Cu}$ was observed in the shoots of Guizotia abyssinica (L.f) Cass. var, RCR-18 variety when the plants supplemented with AM fungi over the control plants. There was also an increase in the seeds and dry matter of shoots with $50 \%$ and $75 \%$ of recommended dose of phosphate with AM fungi in Guizotia abyssinica (L.f) Cass.var, RCR18. 


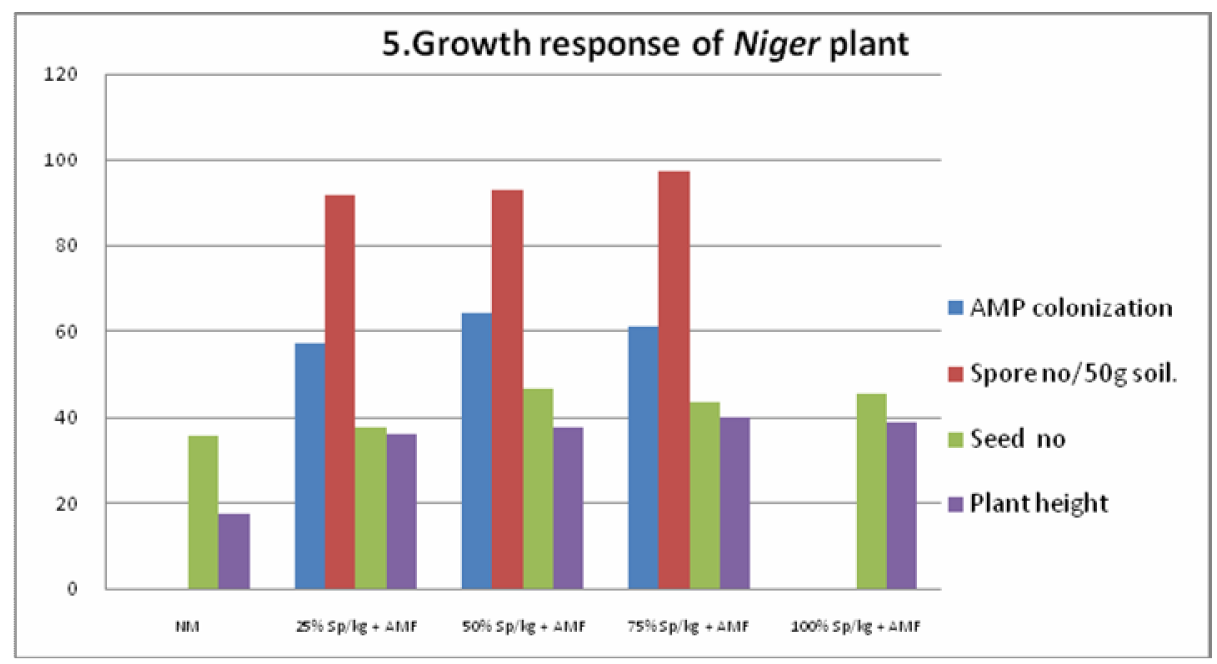

Fig. 5. Effect of different dosages of phosphate and AM fungus Scutellospora nigra, Glomus mosseae on growth of Guizotia abyssinica (L.f) Cass RCR-18 var at 90 days.

Our findings are in consistent with the earlier works of Srinivasulu, (2002). Lakshman and Kolkar, (2008) showed that $75 \%$ of recommended dose of super phosphate was favorable to GPU-45, RAU-8 showed significantly increased in plant height, percent colonization and spore number in Niger plant. The present results are in consistent with the findings of earlier workers in other crop plants (Plenechette and Morel-1996, Sreenivasa1994, Kelly et al. 2001, Maruthi 2013). This confirms that $25 \%$ of recommended dose of phosphate fertilizer could be saved in Niger by inoculating with Glomus mosse. Diaz et al., (1946) had reported the uptake of heavy metals ( $\mathrm{Al}, \mathrm{Cu}, \mathrm{Pb}$ ) and their influence on the growth of Lygeusu spartna and Anthyllis cystisoides after mycorrhizal inoculation.

Liu et al. (2000) had detected acquisition of $\mathrm{Cu}, \mathrm{Zn}, \mathrm{Mn}$ and Fe in mycorrhizal Maize (Zea may L). However, further increase in ' $P$ ' dose significantly decreased plant height, dry weight of shoot and root, root colonization and spore number in all the two verities of Niger. Growth of AM fungus in the host root was better when supplied with lower dose of 'P' fertilizer (Harley and Smith 1983, Sieverding and Howler 1985, Srinivasulu 2002, Lakshman 2009, Tanwar et al. 2013). Over all Niger plants supplemented with different levels of phosphate with AM fungal Scutellospora nigra as showed maximum plant growth and yield of Guizotia abyssinica (L.f) Cass.var, RCR-18 at 50\% PD sp/kg with AM fungus Glomus mosseae inoculation. Soil microorganisms play a vital role in solubalization of mineral compounds into soluble forms. Liu et al. (2000) have showed remarkable increase in growth and P uptake in AM inoculated Zea mays plants. Marschner and Dell (1994) reported that high phosphate fertilizer significantly caused decrease in the number of chalmydospores of Glomus fasciculatum. AM Fungal spore production can be more or less application of phosphorous rich fertilizers. On the other hand, Roa and Maruthi (2013) have stated that there is reduction in AMF sporulation on application of fertilizers. Similarly Bagyaraj and Manjunath (1980) have conducted investigation on the effect of Glomus fasciculatum on growth and nutrient uptake in three crop plants viz., cotton, cowpea and finger millet in soil with low phosphorus content. They found that AM inoculated plants showed significant increase in shoot and root biomass. Further, phosphorus and zinc content was found to be higher when compared to control plants. Reduction in fertilizer in put on application of beneficial microbes has been reported by Soleimanadeh (2010) who have suggested the use of AM fungi with $50 \%$ recommended phosphorus to increase seed yield and oil production in sunflower. Influence of mycorrhizal fungi and phosphorus fertilizer was clearly demonstrated by Sieverding and Howler (1985) on cassava. Sreenivasa in (1992) have found that there was an increase in the uptake of micronutrient viz., Zn, 
$\mathrm{Mn}, \mathrm{Ca}$, and $\mathrm{Fe}$ in addition to $\mathrm{P}$, in chilli plants that were inoculated with Glomus macrocarpum. Srihari el al. (1995) has conducted experiments to study the effect of Glomus fascicularum in sunflower plants and they found that AM fungi inoculated plants showed better growth with low dosage of super phosphate treatment.

\section{Conclusion}

Decrease in mycorrhizal colonization and AM fungal spore number after the use of 50\% RDSP/kg with AM fungi Scutellospora nigra and Glomus mosseae in Guizotia abyssinica (L.f) Cass.var, RCR-18. The use of supplemented 50\% RDSP/kg with AM fungus Scutellospora nigra can be recommended for Guizotia abyssinica (L.f) Cass.var, RCR-18. Overall, our results clearly suggest that synergistic or additive mechanisms are involved in the improvement of plant growth, nutrient uptake and adaptation to unfavorable drought soil conditions

\section{Acknowledgement}

The authors are thankful to DST-SERB for financial support and sanctioning the major research project experimental studies on the additive effect of PGPR and hydrolytic enzyme in Niger plants infected with AM fungi.

\section{References}

Bagyaraj D J. 2006. Arbuscular mycorrhizal fungi in sustainable agriculture In: Techniques in mycorrhizae P.1-8 Eds. M.J Bukhari and B.P Rodrigues Department of Botany. Govt Arts, Science and Commerce Collage Quepem Goa.

Bagyaraj DJ, Manjunath A. 1980. Selection of a suitable host for mass production of Arbuscular mycorrhizal inoculum, Plant and Soil. 55, 495-498. http://dx.doi.org/10.1007/BF02182709

Bremmer J M. 1960. Determination of nitrogen in soil by Kjeldahl method. J Agric Sci 55:11-33. http://dx.doi.org/10.1017/S0021859600021572

Brundrett M N, Bougher B Dell, T Grove, N Malajczuk.1996. Working with Mycorrhizas in Forestry and Agriculture. ACIAR Monograph 32, 347.

Diaz G, Azcdn-Aguilar C, Honrubia M. 1996. Influence of arbuscular mycorrhiza on heavy metal ( $\mathrm{Zn}$ and $\mathrm{Pb})$ uptake and growth of Lygedum spartum and Anthyllis cytisoides. Plant Soil 180, 241-249. http://dx.doi.org/10.1007/BF00015307

Fusconi A, Lingua G, Trotta A, Berta G .2005. Effects of Arbuscular colonization and phosphorous application on nuclear ploidy Allium porrum plants. Mycorrhiza.15, 313-321. http://dx.doi.org/10.1007/s00572-004-0338-x

Gerdemann J W, Nicholson T H. 1963. Spores of Mycorrhizal endogone spp. Extracted from soil by wet-sieving and decanting Method. Transactions of the British Mycorrhizal Society 46, 235-244. http://dx.doi.org/10.1016/S0007$\underline{1536(63) 80079-0}$

Giovanneti M, Mosse B. 1980. An evolution of technique for measuring vesicular arbuscular Mycorrhizal infection in roots. New Phytologist 84, 489-500. http://dx.doi.org/10.1111/j.1469-8137.1980.tb04556.x

Harley J L, Smith S E. 1983. Mycorrhizal Symbiosis, Academic Press, London, UK, 483 pp.

Jackson M L .1973. Soil chemical Analysis. Prentice Hall Pvt. Ltd. New Delhi. India.

Kaleem M. 2000. Manures and Fertilizers. In: Hand book of Agricultural Science. Ed Singh. Kalyani Publisher's. New Delhi, 828 pp.

Kapoor K K, Misra M M, Mukreja K. 1989. Phosphate solubilization by soil microorganisms; a review. Indian J Microbiol. 29, 119-127.

Lakshman H C. 2008. Effects of AM fungus with additional P on the growth of Hibiscus rosasinenusis, Nat J Life Sci 5(2),191-196.

Lakshman H C. 2009. Effects of AM fungus with additional P on the growth of Brassica junceacea L Cruciferace In: J Plant Sci 1(1), 52-55. 
Liu A, Hamel C, Hamilton R I, Smith D L.2000. Acquition of Cu, Zn, Mn and Fe by mycorrhizal Zea mays L. grown in soil at different $P$ and micronutrients levels. Mycorrhiza 9:331-336. http://dx.doi.org/10.1007/s005720050277

Marschner H, Dell B.1994. Nutrient uptake in mycorrhizal symbiosis. Plant and Soil 159, 89-102.

Mauritz V, Sanna and Kukkone (2008) Performance of AM fungi in peat substrates in greenhouse and field studies. COST 870 meeting "From production to application of AM fungi in agricultural systems: a multidisciplinary approach". Denmark, May 27-30. pp 25-26.

Mosse B.1973. Advances in the study of Vesicular-arbuscular mycorrhiza. Ann Rev Phytopathol 11, 171-196. http://dx.doi.org/10.1146/annurev.py.11.090173.001131

Mosse B, Jones G W.1975. Separation of endogone spores from organic soil debris by defferential sedimentation on gelatin column. Trans Br Mycol Soc 51(5),604-608.

Phillips J M, Haymann D S.1970. Improved procedures for clearing roots and staining parasitic and vesicular-Arbuscular Mycorrhizal fungi for rapid assessment of infection.Transactions. British Mycological Society 55,158-161. http://dx.doi.org/10.1016/S0007-1536(70)80110-3

Plenchette C, Fortin J A, Furlan V.1983. Growth response of several plant species to mycorrhiza in a soil of moderate $P$ fertility. I: mycorrhiza dependency under field conditions. Plant and Soil 70(2),191-209. http://dx.doi.org/10.1007/BF02374780, http://dx.doi.org/10.1007/BF02374781,

Ross J P.1971. Effect of phosphate fertilization as yield of Mycorrhizal and non -Mycorrhizal soybeans. Phytopathol 61,1400-1403. http://dx.doi.org/10.1094/Phyto-61-1400

Sieverding E, Howler R H.1985. Influence of species of VA -Mycorrhizal fungi on Cassava field response to Phosphorus fertilization. Plant and Soil 88, 213-221. http://dx.doi.org/10.1007/BF02182447

Smith S E, Smith F A. 2011. Roles of Arbuscular mycorrhizas in plant nutrition and growth: new paradigms from cellular to ecosystem scales. Ann. Rev. Plant Biol 62, 227-250. http://dx.doi.org/10.1146/annurev-arplant-042110-103846 PMid:21391813

Soleimanzadeh H. 2010. Effects of AM fungus on growth and yield of sunflowers at different phosphorus levels. World Acad Sci EG Technol 71, 414-417.

Sreenivasa M N. 1992. Selection of efficient vesicular arbuscular mycorrhizal fungus (Capsicum annum Linn). Scientia Horticulture 50, 53-58. http://dx.doi.org/10.1016/S0304-4238(05)80008-1

Srihari P C, Sreenivasa M N. 1993. possible synergistic interaction between G.marcocarpum and B.ploymyxa in Chilli: Biofertilizers for future .Proceedings of III National conference on Mycorrhizae. Eds. Adholeya A and Singh.S TERI . New Delhi: 180-183pp.

Srinivasa M N .1994. Response of Chili to vesicular Arbuscular mycorrhiza at different phosphorus levels in field. Indian J Agri Sci 64, 47-49.

Srinivasulu Y. 2002. VA mycorrhizal studies on some varieties of Guizotia abyssinica (L.f) Cass. Ph .D Thesis. Karnatak University Dharwad. India.

Tanwar A, Aggarwal A, Krishna Neethu. 2012. Effectiveness of endo mycorrhizal fungi and $P$. flouresence under different phosphorous level on Capsicum annum L. Kasetsart. J Nat Sci 46, 769-682. 